\title{
Bridging Social Media Technologies to Enhance Destination Image and Recommendation Intention Towards Mobility Program Among International Students in Malaysian Public Universities
}

\author{
Subramaniam Govindan* \\ School of Chemical Sciences \\ Universiti Sains Malaysia \\ Penang, Malaysia \\ subrag@usm.my
}

\author{
Salmi Mohd Isa \\ Graduate School of Business \\ Universiti Sains Malaysia \\ Penang, Malaysia \\ salmi.mohd.isa@usm.my
}

\author{
Anil Kumar Om Parkash \\ Air Products Malaysia \\ Kulim, Malaysia \\ anilkuop@airproducts.com
}

\begin{abstract}
Malaysia is transforming and growing into an international educational hub. Malaysia is among the top $11^{\text {th }}$ world ranking exporter in the scholarly discipline. However, there is lack of empirical study on mobility programme in higher learning institution. Recently, social media technologies become popular among students.Given that the empirical study of student mobility is in an undeveloped state, this research describes efforts to explore and investigate factors that have a significant influence on recommendation intentions of international students towards mobility program. Based on the 309 international students from five public universities participated in this study, findings reveal that social media mediates a relationship with destination image and recommendation intention towards mobility programs. The analyses reveal that social media has direct links with destination image and recommendation. In this regards, social media technologies received trust from it users towards enhancing destination image and recommendation of mobility programme.
\end{abstract}

Keywords: mobility program, social media technologies, destination image, recommendation intentions

\section{INTRODUCTION}

Higher learning institution play an essential role in education, research, and innovation. It has become a vital determinant of the growing importance of intellectual capital in today's competitive global socio-economic landscape. Higher educational institutions explicitly view international education as a form of economic development. Therefore it has led to the expansion of institutions to design the best-fit curriculum, offer various types of educational programs for international students, and to create synergy through partnership. Consequently, to be effective, these partnerships need to find an organization that can support a synergistic process as well as directs the implementation of the programs. Internationalization and globalization have changed the way the world works. Hence, employers and industries prefer to hire fresh graduates with competency and skills rather than graduates with a degree even from an elite university. Studying abroad has been viewed as an essential component of a university degree, for their personal and professional development, an opportunity to build critical understanding and preparing for future leaders with the global mindset [1,2]. Therefore, higher learning institutions have flagged student mobility programs as a platform for internationalization. Their higher education system structured as part of a broader project to attract a significant number of international students into mobility programs. Mobility programs are frame as a means of providing students with opportunities to acquire intercultural skills, multicultural outlooks, and awareness of global issues. Also, this program sets a platform for students to gain overseas employment market opportunities, make lifelong friends from a different region of the world and strengthen economic integration by building a collaborative network through sharing of information between the areas [3]. Further, the mobility programs help the Educational Institutions increase and improve their visibility towards global university rankings, thus attracting international students.

This research aims to determine the impact of social media technologies on international student's recommendation intention and to examine the mediating role of destination image between social media technologies and recommendation intention towards mobility programs in public universities in Malaysia. This study fills the gap in higher education works of literature of mobility program by identifying the influence of social media, and destination image on recommendation intention and guides for universities' policymakers to be aware of the importance of the international student-as-customer market and determine the number of international students who intend to take part in mobility programs.

\section{MATERIALS AND METHODS}

\section{A. Literature Review}

In the era of digital technology disruptive changes and with the advent of Industry 4.0, the mobility program gives a golden opportunity for mobile program participants in experiential, social, and theoretical learning to experience and feel the real global working environment at a prestigious industry abroad. The program offers on-the-job training 
in promoting mobility programs through viral nature dissemination. For example, 270 million Gen Y age between 18-24 years is actively using Instagram daily [6]. Subsequently, it is very energetic for industries to know how to deal with social media technologies and a capable tool for attracting more participants to enroll in the mobility program. Moreover, concerning the institution's performance, entering a significant number of international students for a mobility program using social media engagement helps to make awareness of new products/services and branding. Also, it leads to institution ranking, high revenue, and consequently developing secure networks.

Social media sites such as Facebook, Youtube, LinkedIn, forums photo sharing, video sharing, twitter, and blogs provide a technology platform to establish and multiply relationships between users and institutions. It becomes an essential channel for transforming marketing communications through sharing and learning from online information. It plays a focal role in the development of new relationships, attachment, and creating an opportunity for the educational institution to engage with students and to dissemination relevant information about marketing their offerings. Each year, the social network is enjoying phenomenal success, which gives some great insights into the world of social media. For instance, the number of internet users worldwide in 2018 is 4.021 billion, up 7 percent year-on-year, while social media users are 3.2 billion each month, with almost all of those users accessing their chosen technologies platform via a mobile device. Facebook, a social networking website, claims that its active users reached 2.2 billion worldwide, more than 50\% of which log in every day [5]. This causes a paradigm shift in influencing society to share cutting-edge information, strengthen customer relationships by encouraging customers to engage with their brands.

For the education industry, social media serves the purpose of becoming the best instrument to reach customers globally and receive their valuable feedback. It can help them to advertise their mobility program at very meager rates or in some cases, entirely free. As a result, higher education institutes have looked for the most effective marketing strategy with minimum cost. Social media has become an excellent choice that serves this strategy because it can reach millions of people with the highest speed, and it can spread out very quickly; then the education industry prefers to use social media even in substitution to the traditional media tools.

A worldwide survey discovered that $90 \%$ of Gen Y checks their social media websites before they even get out of bed. Gen Y has been exposed to the latest technological advancement and has immediate access to information. Different approaches to their attitudes and behaviors can reach a broader audience and a desire for stimulating personal growth, first hand information that shakes up their routine, engaging their senses, career choices, and lifestyles. Consequently, marketers realized the influence of social media on Gen Y does not only able to foster new business ventures but also play a significant role

\section{B. Research Framework}

The study applies Ajzen's Theory of Planned Behavior (TPB) as a theoretical basis for identifying the factors which might influence their recommendation intention towards mobility programs in Malaysia Higher Education Institutions. TPB theory has been widely used to understand how different types of beliefs motivate intention and actual behavior [7]. The elements of TBP are reflective of categories of factors that have demonstrated as necessary in the context of mobility programs. The theory has been used to measure predicting study about recommendation intentions, and it applies perfectly to understanding the factors that influence international students for mobility programs [8]. The mixture of attitudes, subjective norms, and perceived behavioral in TPB theory form a behavioral. It refers to the person's perception to carry out behavior, which is ease or difficulty in performing the action or reachable. Perceived behavioral control considered as the factor that influences the given reaction, which refers to the total of the individual's actual control of the behavior and his or her perceptions about this control. The intention is used to capture what is the motivational factors that influence individuals' behavior [9].

The theoretical framework for this study in figure 1 reflects the TPB model [10] because all the factors reflect the international student's recommendation intention towards the mobility program. Subsequently, this study examined the relationship between independent variable dimensions and destination image as a mediator, and recommendation intention towards the mobility program as a dependent variable. Thus, analysis of this research will benefit Malaysian public universities by providing information on the elements that universities management needs to focus on to encourage more international students to participate in mobility programs in the future.

Based on the proposed model, the following hypothesis has developed.:

H1: Social Media has a positive and significant relationship with recommendation intention

$\mathrm{H} 2$ : Social Media has a positive and significant relationship with the destination image 
0.943 , which exceeds the recommended value of 0.70 given by [11]. Thus, this study ensured the existence of convergent validity. Therefore, this study found that the AVE of all the constructs fulfills the recommended cut-off value. Further, the results of this study, found the range of 0.76 to 0.98 , as composite reliability, which surpasses the cut off value 0.7 . Thus, this study ensured the existence of convergent validity.

SEM statistical techniques were conducted using Smart - PLS analysis on 309 samples. It applies to assess the measurement model, and this is required to determine how good the measurement items were when they loaded on theoretical define constructs. The measurement model's overall goodness of fit was examined before proceeding to assess the degree of correlation between the measurements in one construct [11]. Table 1 shows the indicator loadings for all the items that exceeded the recommended value of 0.708 , as suggested by [11]. The AVE of all variables was in the range of 0.718 to 0.802 , which exceeds the recommended value of 0.50 , and $\mathrm{CR}$ ranges from 0.924 to 0.943 , which exceeds the recommended value of 0.70 given by [11]. Thus, this study ensured the existence of convergent validity. Therefore, this study found that the AVE of all the constructs fulfills the recommended cut-off value. Further, the results of this study, found the range of 0.76 to 0.98 , as composite reliability, which surpasses the cut off value 0.7 . Thus, this study ensured the existence of convergent validity.

\section{Reliability and Validity}

Recently [16] developed a new criterion for measuring discriminant validity. The authors using simulation studies demonstrated that in comparison to old criterions like Fornell \& Larcker [17] criterion and cross-loadings are inadequate in measuring discriminant validity. Therefore, they suggested two different cut-off values of 0.85 and 0.90 for the HTMT criterion to establish discriminant validity. This study used a more conservative level of 0.85 (i.e., HTMT.85) to determine the discriminant validity of the model. Table 2 shows that the discriminant validity of the model established since all the results of the HTMT.85 criterion was below the critical value of 0.85 . In total, the measurement model demonstrated adequate convergent validity and discriminant validity. As shown in Table 2.

The results show that every value is below 0.85 . Nevertheless, the value is seen as valid if it is below 0.9 [16]. Thus, the HTMT ratio criterion fulfilled in the present study.

\section{E. Structural Model}

In the research model, to assess the structural model by using the path coefficient with bootstrapping technique, which had utilized for 309 samples. The significance of the path coefficient determined by comparing the t-values to the critical t-values for significance levels of 0.05 and 0.01 . Bootstrapping was used to compute the empirical t-value for the significance of path coefficients using 1000 subsamples as recommended by [11]. Table 3 tabulates the path coefficients obtained from the analysis to assess the statistical significance in the structural model. The results of 
data analysis revealed that social media has no relationship with recommendation intention as $\beta=0.021$ at $p>0.05$; therefore, $\mathrm{H}^{1}$ was found not supported. The results of directs effects on social media were found supported to destination image at $\beta=0.238$ at $\mathrm{p}>0.01$. The research model tested the independent variables with a mediator variable destination image between social media and recommendation intention. The results shows that standardized beta value at $\beta=0.174$ at $p>0.01$ is significant.

The path coefficient and significance level of the relationships were used to test the hypotheses. The results of the data analysis were used to classify the hypotheses as supported and not supported. In total, two direct hypotheses and one indirect hypothesis were tested from the research framework. Out of the three hypotheses tested, two hypotheses were supported, and one hypothesis was not supported.

\section{DISCUSSION}

The results of the study provide new exciting information to practicing managers, and the outcomes can be helpful to develop strategies and improve services by the providers. The review was not only theoretically informed but also has practical implacability and acceptable execution. The contributions made by academic research should be functional and free from complexity so that results can be implemented easily in the actual environment. Since the two hypotheses are supported, this study established the importance of social media in the context of mobility program destination image has a direct impact between destination image and recommendation intention towards mobility program. Social media are seen as a new point in the evolution of the world's digital network among the young generations. But findings indicate that social media regarding mobility programs do not have a significant direct influence on recommendation intention. The reason for the non-significant relationship could be sourced from information that could not be trusted by one party. In general, most respondents believe the destination image and reassurance from family, friends, education agents, education fairs, and recommendation from an academic advisor is more genuine, as well as that shared views on social network sites make them think twice.

This finding gives eye-opening information in the context of the recommendation intention of international students. The results suggest that it is not the physical characteristics of universities and institutions that directly associated with the recommendation intention of international students. It is the perception about the destination image, which means the whole country, by safety and security, culture, places of attraction, and political stability that guide students about the recommendation of a destination image. The findings of this study reveal the perception of the destination image in Malaysia as the destination of higher education is the essential factor that develops recommendation intention among the inbound mobility program students.

\section{CONCLUSION}

Mobility program has become one of the global agendas amongst the higher education institution landscape. International student's participation in the mobility program allows them to share their knowledge and valuable experience while staying in the host country. The recommendation intention will encourage potential future academic and professional relationships. Moreover, the host institution can leverage on social media technologies to position themselves in the growing international education hub in the region. Apart from that, mobility programs are creating a high chance of international students who participate in the mobility programs to return to pursue postgraduate studies in Malaysian universities. Therefore social media technologies are not only a method of sharing information but also have had a far-reaching impact on society. The implications of moving towards technologies in the digital era are vast and help bridging the academic community to re-learn and co-learn.

\section{REFERENCES}

[1] M. D. Azzwan and A. E. Azhar, "Student mobility and knowledge transfer in Malaysia: A case study of a renowned public university," Geografia-Malaysian Journal of Society and Space, vol. 12.9, 2017.

[2] A. Samokhvalova, "Branding higher education: The case of Malaysian higher education promotion on the Internet," Kajian Malaysia, vol. 35.2, 2017, pp. 87-104

[3] S. Khoroshilova, E. Kostina, L. Bezdenezhnykh, T. Vezirov, and V. Shibaev, "Academic mobility: The impact of short-term language courses abroad on the development of language competences," Procedia-Social and Behavioral Sciences, vol. 214, 2015, pp. 992-999.

[4] L. J. ChanLin and W. H. Hung, "Evaluation of an online internship journal system for interns," Procedia-Social and Behavioral Sciences, vol. 191, 2015, pp. 1024-1027.

[5] Facebook, "Platform," newsroom.fb.com/Platform, 2018.

[6] C. Hatch, Social Media Trends to Consider, DISRUPTIVE ADVERTISING, disruptiveadvertising.com, 2018.

[7] C. J. Armitage and M. Conner, "Efficacy of the theory of planned behaviour: A meta-analytic review," British journal of social psychology, vol. 40.4, 2001, pp. 471-499.

[8] I. Ajzen, "The theory of planned behavior," Organizational behavior and human decision processes, vol. 50.2, 1991, pp. 179-211.

[9] E. Autio, R. H. Keeley, M. Klofsten, G. G. C. Parker, and M. Hay, "Entrepreneurial intent among students in Scandinavia and in the USA," Enterprise and Innovation Management Studies, vol. 2.2, 2001, pp. 145-160.

[10] O. Schnusenberg, P. De Jong, and L. Goel, "Predicting study abroad intentions based on the theory of planned behavior," Decision Sciences Journal of Innovative Education, vol. 10.3, 2012, pp. 337 361.

[11] J. F. Hair, G. T. M. Hult, C. Ringle, and M. Sarstedt, A primer on partial least squares structural equation modeling (PLS-SEM), Sage publications, 2016

[12] M. S. Garver and J. T. Mentzer, "Logistics research methods: employing structural equation modeling to test for construct validity," Journal of business logistics, vol. 20.1, 1999, pp. 33.

[13] J. W. Hoelter, "The analysis of covariance structures: Goodness-offit indices," Sociological Methods \& Research, vol. 11.3, 1983, pp. 325-344.

[14] R. B. Kline, Principles and practice of structural equation modeling, Guilford publications, 2015. 
[15] P. W. Lei and Q. Wu, "Introduction to structural equation modeling: Issues and practical considerations," Educational Measurement: issues and practice, vol. 26.3, 2007, pp. 33-43.

[16] J. Henseler, C. M. Ringle, and M. Sarstedt, "A new criterion for assessing discriminant validity in variance-based structural equation modeling," Journal of the academy of marketing science, vol. 43.1, 2015, pp. 115-135.

[17] C. Fornell and D. F. Larcker, "Structural equation models with unobservable variables and measurement error: Algebra and statistics," 1981, pp. 382-388.

\section{APPENDIX}

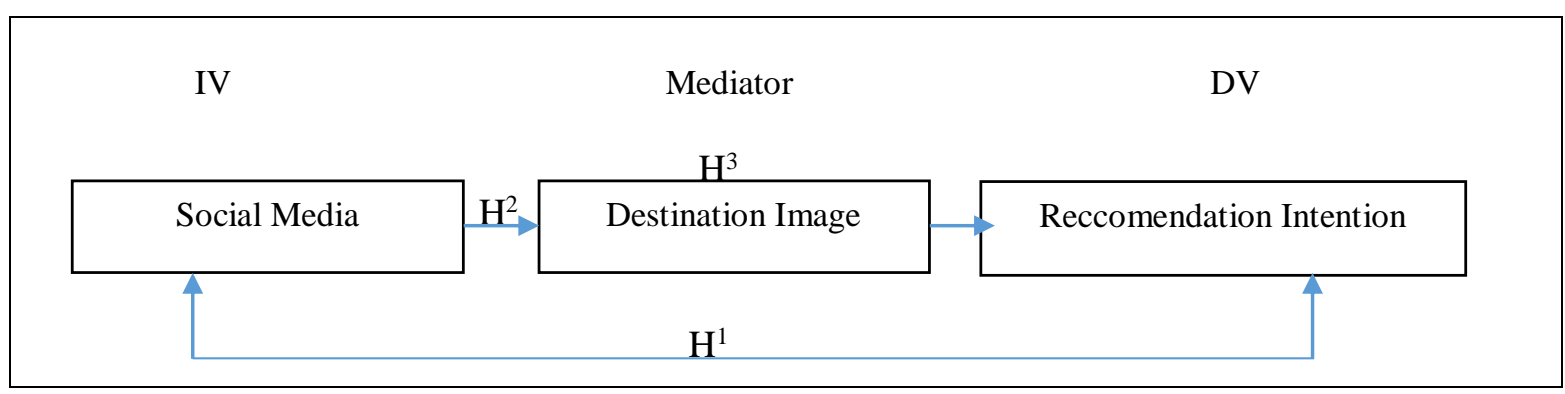

Fig. 1. The theoretical framework for this study

TABLE 1. RESUlts OF MEASUREMENT MODELS

\begin{tabular}{lcccc}
\hline \multicolumn{1}{c}{ Latent Variable } & Item & Factor Loading & CR & AVE \\
\hline Social Media & SM1 & 0.840 & & \\
& SM2 & 0.894 & 0.943 & 0.768 \\
& SM3 & 0.902 & & \\
& SM4 & 0.886 & & \\
& SM5 & 0.861 & 0.939 & \multirow{2}{*}{0.718} \\
& D1 & 0.839 & & \\
& D2 & 0.838 & & \multirow{2}{*}{0.802} \\
& D3 & 0.880 & 0.924 & \\
\hline Destination Image & D4 & 0.856 & & \\
& D5 & 0.868 & & \\
& R1 & 0.901 & & \\
& R2 & 0.970 & & \\
& R3 & 0.877 & & \\
\end{tabular}

$\overline{C R}=$ Composite Reliability, $A V E=$ Average Variance Extracted

TABLE 2. HTMT DisCRIMINANT VALIDITY (HTMT ${ }_{85}$ CRITERION)

\begin{tabular}{lccc}
\hline \multicolumn{1}{c}{ Construct } & Destination Image & Recommendation Intention & Social Media \\
\hline Destination Image & - & - & - \\
Recommendation Intention & 0.620 & - & - \\
Social Media & 0.640 & 0.460 & 0.652 \\
\hline
\end{tabular}

TABLE 3. RESULTS OF STRUCTURAL MODEL ANALYSIS

\begin{tabular}{ccccccc}
\hline Hypothesis & Relationship & Beta & SE & T-value & P-value & Decision \\
\hline $\mathrm{H}^{1}$ & SM -> RI & 0.021 & 0.088 & 0.238 & 0.406 & Not supported \\
$\mathrm{H}^{2}$ & SM -> DI & 0.238 & 0.097 & 2.489 & 0.068 & Supported \\
$\mathrm{H}^{3}$ & SM -> DI-> RI & 0.174 & 0.05 & 3.502 & 0.001 & Supported \\
\hline
\end{tabular}

SM: Social Media: DI: Destination Image: RI: Recommendation Intention 